\title{
The effect of metal salts on quantification of elemental and organic carbon in diesel exhaust particles using thermal-optical evolved gas analysis
}

\author{
Y. Wang ${ }^{1}$, A. Chung ${ }^{1, *}$, and S. E. Paulson ${ }^{1}$ \\ ${ }^{1}$ Department of Atmospheric and Oceanic Sciences, University of California at Los Angeles, Los Angeles, \\ California 90095-1565, USA \\ *now at: AMEC Geomatrix, Inc. Newport Beach, CA 92663, USA
}

Received: 13 June 2010 - Published in Atmos. Chem. Phys. Discuss.: 9 July 2010

Revised: 18 November 2010 - Accepted: 19 November 2010 - Published: 3 December 2010

\begin{abstract}
Thermal-optical evolved gas analysis (TOEGA) is a conventional method for classifying carbonaceous aerosols as organic carbon (OC) and elemental carbon (EC). Its main source of uncertainty arises from accounting for pyrolized OC (char), which has similar behavior to the EC originally present on the filter. Sample composition can also cause error, at least partly by complicating the charred carbon correction. In this study, lab generated metal salt particles, including alkali $\left(\mathrm{NaCl}, \mathrm{KCl}, \mathrm{Na}_{2} \mathrm{SO}_{4}\right)$, alkaline-earth $\left(\mathrm{MgCl}_{2}, \mathrm{CaCl}_{2}\right)$ and transition metal salts $\left(\mathrm{CuCl}_{2}, \mathrm{FeCl}_{2}\right.$, $\left.\mathrm{FeCl}_{3}, \mathrm{CuCl}, \mathrm{ZnCl}_{2}, \mathrm{MnCl}_{2}, \mathrm{CuSO}_{4}, \mathrm{Fe}_{2}\left(\mathrm{SO}_{4}\right)_{3}\right)$, were deposited on a layer of diesel particles to investigate their effect on EC and OC quantification with TOEGA. Measurements show that metals reduce the oxidation temperature of EC and enhance the charring of OC. The split point used to determine classification of EC vs. OC is more dependent on changes in EC oxidation temperature than it is on charring. The resulting EC/OC ratio is reduced by $0-80 \%$ in the presence of most of the salts, although some metal salts increase reported $\mathrm{EC} / \mathrm{OC}$ at low metal to carbon ratios. The results imply that EC/OC ratios of ambient aerosols quantified with TOEGA have variable low biases due to the presence of metals. In general, transition metals are more active than alkali and alkaline-earth metals; copper is the most active. Copper and iron chlorides are more active than sulfates. The melting point of metal salts is strongly correlated with the increase of OC charring, but not with the reduction of EC oxidation temperature. Other chemistry, such as redox reactions, may affect the EC oxidation. A brief discussion of possible catalytic mechanisms for the metals is provided.
\end{abstract}

Correspondence to: S. E. Paulson (paulson@atmos.ucla.edu)

\section{Introduction}

Ambient aerosols are composed of inorganic species, such as sulfate, nitrate, ammonium, trace metals, and carbonaceous material consisting principally of OC and EC (also known as black carbon, BC). Carbonaceous materials make up a large fraction of ambient aerosols (Zhang et al., 2007). OC and EC play important roles in climate, heath and other atmospheric processes, thus there is great interest in quantifying $\mathrm{OC}$ and EC in aerosol particles.

Carbonaceous aerosol ranks as some of the most difficult aerosol to measure, with uncertainties of at least 30-50\% (e.g., Huebert and Charlson, 2000). OC and EC are usually determined by thermal-optical protocols. One such protocol is the National Institute of Occupational Safety and Health (NIOSH) method 5040 with correction by thermaloptical transmission (TOT) (Chow et al., 2001; NIOSH, 1999). Briefly, a filter sample is exposed to a prescribed temperature protocol first in an inert (helium, He) environment and then in an oxidizing (He/oxygen mixture, $\mathrm{He} / \mathrm{O}_{2}$ ) atmosphere. Ideally, OC volatilizes in the He-mode of the analysis, while EC combusts in the oxidizing atmosphere at high temperatures. A major complication is that a fraction of the OC chars, or pyrolyzes, in the inert mode of the analysis. This pyrolyzed organic carbon (POC) requires an oxidizing atmosphere to evolve off the filter, similar to EC. To account for pyrolysis, the transmittance of laser light through the sample is monitored and used to split the total carbon (TC) into OC and EC. The OC-EC split is generally defined as the point where the transmittance level returns to its initial level after a transient reduction of laser response due to OC charring. This point frequently intersects a large peak, so that a shift in the peak by a few seconds in either direction has a significant impact on the carbon mass allocated as OC or EC.

Published by Copernicus Publications on behalf of the European Geosciences Union. 
A handful of studies have suggested the sample composition, either organic or inorganic, can influence the evolution of carbon from filters, causing errors in TOEGA (Peterson et al., 2001). EC in aged and remote aerosols has been observed to evolve at considerably lower temperatures (450$550^{\circ} \mathrm{C}$ instead of $550-700^{\circ} \mathrm{C}$ ) than in urban aerosols (Huffman, 1996). EC in ambient aerosols evolved at $30-40^{\circ} \mathrm{C}$ lower temperatures than in highway vehicle samples (Turner and Hering, 1990). EC in biomass-burning aerosols was also oxidized at lower temperatures compared to diesel particles (Novakov and Corrigan, 1995a). Mixing ambient aerosols with tunnel exhaust can lower diesel soot oxidation temperatures by $100-150{ }^{\circ} \mathrm{C}$, a phenomenon attributed to the noncarbonaceous constituents of particles (Turner and Hering, 1994; Grosjean et al., 1994). A suite of laboratory studies demonstrated that small amounts of many metals $(\mathrm{Na}, \mathrm{K}, \mathrm{Ca}$, $\mathrm{Mg}, \mathrm{Cu}, \mathrm{Fe}, \mathrm{Mn}, \mathrm{Zn}$ ), either as oxides or salts, can lower the temperature and increase the rate of oxidation of diesel soot (Murphy et al., 1981; Novakov and Corrigan, 1995a; Grosjean et al., 1994; Lin and Friedlander, 1988; Stanmore et al., 2001; Neeft et al., 1996). Generally transition metal oxides $\left(\mathrm{CuO}, \mathrm{MnO}_{2}, \mathrm{Fe}_{2} \mathrm{O}_{3}\right)$, and especially copper (Murphy et al., 1981; Neeft et al., 1996; Bonnefoy et al., 1994; MorenoCastilla et al., 1985), have been found to be more active than others $(\mathrm{CaO}, \mathrm{MgO})$ in oxidizing soot. In some studies, the oxidation reactivity of graphite or soot was found to increase in rough proportion to the catalyst to soot ratio (e.g., Lin and Friedlander, 1988; Neeft et al., 1998). In other studies, this ratio was found to have much less influence (Turner and Hering, 1994; Grosjean et al., 1994).

Charring of organic materials is the subject of an extensive literature investigating the use of metals to catalyze the pyrolysis of cellulose, wood and coal (Varhegyi et al., 1988; Richards and Zheng, 1991; Ponder and Richards, 1994). $\mathrm{K}^{+}, \mathrm{Ca}^{2+}, \mathrm{CuCl}_{2}, \mathrm{CuSO}_{4}, \mathrm{FeCl}_{2}, \mathrm{KCl}, \mathrm{FeCl}_{3}, \mathrm{FeSO}_{4}$, $\mathrm{Fe}_{2}\left(\mathrm{SO}_{4}\right)_{3}, \mathrm{NaCl}$ and $\mathrm{ZnCl}_{2}$ have all been shown to increase the char yield, while $\mathrm{MgCl}_{2}$ has not. More char is produced at higher concentrations of $\mathrm{ZnCl}_{2}$ and $\mathrm{Fe}_{2}\left(\mathrm{SO}_{4}\right)_{3}$.

The behavior of the catalyst appears to depend on factors such as catalyst loading, heat treatment of the sample, carbon oxygen group content, dispersion, and chemical state of the catalyst. Although some efforts have been made, the catalytic community has not thus far been successful at developing a predictive model for metal catalytic activities, and thus relies primarily on empirical observations.

Diesel exhaust particles (DEP) comprise a large fraction of the carbonaceous component of particles, particularly in urban areas (Gray and Cass, 1998). This paper describes the results of a systematic study on the comparative catalytic behavior of 13 metal salts in the measurement of $\mathrm{OC}$ and $\mathrm{EC}$ in DEP, using TOEGA-TOT. Catalytic metals chosen for study are commonly observed in ambient aerosols (Krudysz et al., 2008; IMPROVE, 2010). This study provides a first complete dataset on the effects of metals on the OC and EC measurement by TOEGA, presenting valuable information on the accuracy of TOEGA as a means of determining the OC and EC in DEP.

\section{Experimental}

\subsection{Diesel exhaust particles}

DEP were produced by a four-stroke, air-cooled direct injection 4.8-kW diesel generator (L70V6, Yanmar Corporation) at maximum load. The generator has been verified to produce particles that are well within the range observed for particle emissions from heavy duty diesel trucks in terms of OC and EC content, primary particle size, size distribution and fractal dimension of agglomerates (Chung et al., 2008). The generator was run on California \#2 ultra low sulfur fuel (less than 15 ppmw sulfur), and was allowed to warm up for 10 min prior to collection of samples. DEP were collected $10 \mathrm{~cm}$ away from the generator's exhaust outlet without dilution, onto pre-fired quartz filters ( $47 \mathrm{~mm}$, Pall Life Sciences) at a flow rate of $30 \mathrm{~L} \mathrm{~min}^{-1}$ for $1-2 \mathrm{~min}$. Blanks were collected for $4 \pm 1 \mathrm{~s}$. One set of diesel samples was used as diesel controls; ambient or metal particles were collected on top of the other samples. For diesel samples mixed with metal salts, the engine was operated at load after a $10 \mathrm{~min}$ warm up. For diesel samples mixed with ambient aerosols, the engine was operated under various conditions, resulting in a wider range of initial diesel EC/OC ratios.

\subsection{Ambient aerosols}

Ambient total suspended particles (TSP) were collected on the roof of the math sciences building on the campus of University of California at Los Angeles (UCLA) during 5-7 December 2007. TSP was collected onto Teflon $(47 \mathrm{~mm}$, Pall Life Sciences), quartz, and pre-DEP loaded quartz filters simultaneously, at $30 \mathrm{~L} \mathrm{~min}^{-1}$ for 2 to $6 \mathrm{~h}$. The Teflon filters were used for mass and metal analysis of ambient aerosols. The clean and pre-DEP loaded quartz filters were used for OC and EC analysis of the ambient and the mixed ambient/diesel aerosols, respectively.

\subsection{Metal salt particles}

Thirteen $2.5 \mathrm{wt} \%$ metal salt solutions $\left(\mathrm{NaCl}, \mathrm{KCl}, \mathrm{MgCl}_{2}\right.$, $\mathrm{CaCl}_{2}, \mathrm{FeCl}_{2}, \mathrm{FeCl}_{3}, \mathrm{CuCl}_{2}, \mathrm{CuCl}, \mathrm{MnCl}_{2}, \mathrm{ZnCl}_{2}, \mathrm{Na}_{2} \mathrm{SO}_{4}$, $\left.\mathrm{CuSO}_{4}, \mathrm{Fe}_{2}\left(\mathrm{SO}_{4}\right)_{3}\right)$ were prepared by dissolving the metal salt powders (Acros, Sigma, or Alfa Aesar, purity $>98 \%$ ) in purified de-ionized water $(18 \mathrm{M} \Omega)$. Metal salt solutions were aerosolized into a $2 \mathrm{~m}^{3}$ Teflon chamber for $30 \mathrm{~min}$ at a flow rate of $3.5 \mathrm{~L} \mathrm{~min}^{-1}$. Prior to an experiment, the chamber was flushed with purified air for $1 \mathrm{~h}$, and then filled with purified air for about $15 \mathrm{~min}$. The resulting background particle concentration was $<20 \mathrm{~cm}^{-3}$. The resulting metal salt particles were collected onto pre-DEP loaded quartz filters, usually 
at $30 \mathrm{~L} \mathrm{~min}^{-1}$ for $10-120 \mathrm{~s}$. The sampling time was determined by the desired metal to carbon mass ratio (M/C), typically in the $0.01-0.5$ range, similar to that in ambient aerosols (Krudysz et al., 2008; IMPROVE, 2010). Metal control filters were created by collecting chamber aerosol onto prefired quartz filters at $30 \mathrm{~L} \mathrm{~min}^{-1}$ for $47-540 \mathrm{~s}$. The mass concentrations and size distributions of metal aerosols were monitored with a scanning mobility particle sizer (SMPS, 3081 DMA, 3100 CPC, TSI).

\subsection{OC and EC analysis}

$\mathrm{OC}$ and EC were quantified for $1 \mathrm{~cm}^{2}$ punches of the quartz filter samples with a thermo-optical evolved gas analyzer (Sunset Lab Inc.) using the NIOSH 5040 procedure (NIOSH, 1999; Birch and Cary, 1996). Carbon evolving from the filter is oxidized to carbon dioxide, and then reduced to methane for detection with a flame ionization detector (FID). A red laser $(670 \mathrm{~nm})$ is used to monitor transmittance through the filter. To account for changes in the laser transmittance as the instrument and filter go through its temperature cycle, eighteen diesel samples were first analyzed for OC/EC, allowed to cool, and then re-analyzed. The resulting transmittance curves were averaged, and the resulting "background" curve was used to correct all sample transmittance curves, by taking the natural log of the transmittance through the sample at a given time point relative to the background trace at the same time point ( $\left.\ln \mathrm{I}_{\text {sample- }} \ln \mathrm{I}_{\text {avg.blank }}\right)$. The resulting corrected sample trace was then smoothed with a nine-point moving average. The split point is set as the time at which the corrected transmittance returns to its initial maximum value. This adjusted split time is smaller than, but highly correlated with, the split time set by the instrument software (adjusted split time $=0.83( \pm 0.01) \times$ software split time, $R^{2}=0.41$, $\left.p<10^{-16}\right)$. The adjusted split time $(367 \pm 56)$ has a similar standard deviation as the software split time $(439 \pm 50)$. At the end of each analysis a $5 \% \mathrm{CH}_{4} / \mathrm{He}$ standard is injected for calibration. The measured carbon fractions in $\mu \mathrm{g} \mathrm{cm}^{-2}$ from the analyzer output were converted to total mass in the filter $(\mu \mathrm{g})$. We observe that all of the trends reported in this contribution are preserved if we use the output provided by the instrument software.

Most volatilized carbon evolves in the He phase while the temperature is heated stepwise to $250(90 \mathrm{~s}), 500(60 \mathrm{~s}), 650$ $(60 \mathrm{~s})$ and $850{ }^{\circ} \mathrm{C}(90 \mathrm{~s})$, producing four OC fractions. The $98 \% \mathrm{He} / 2 \% \mathrm{O}_{2}$ atmosphere is introduced after the oven cools to $600^{\circ} \mathrm{C}$, and oxidized carbon evolves at $650(30 \mathrm{~s}), 750$ $(30 \mathrm{~s}), 850(60 \mathrm{~s})$ and $940^{\circ} \mathrm{C}(120 \mathrm{~s})$, producing three EC fractions. The carbon that evolves in the oxidizing atmosphere until the transmitted light returns to its initial value is termed pyrolyzed organic carbon (POC). POC is subtracted from the sum of EC fractions to obtain the EC concentration. $\mathrm{OC}$ is the sum of four $\mathrm{OC}$ and the POC fractions. TC is the sum of OC and EC. OC and EC in blanks were 18.6 $\pm 19.8 \%$ and $2.0 \pm 4.8 \%$ of the samples, respectively.

\subsection{BC analysis}

BC content on the pre-DEP loaded quartz filters was characterized by a dual-wavelength (370 and $880 \mathrm{~nm}$ ) optical transmissometer (Model OT21, Magee Scientific). The relationship between the optical attenuation and the $\mathrm{BC}$ concentration (in $\mu \mathrm{g} \mathrm{cm}^{-2}$ ) is given by $\mathrm{ATN}=\sigma \mathrm{BC}$, where ATN $=-100 \operatorname{In}\left(\mathrm{I} / \mathrm{I}_{0}\right)$, I and $\mathrm{I}_{0}$ are the light intensities transmitted through the loaded and blank filters, and $\sigma$ represents the mass absorption coefficient of BC. We used $16.6 \mathrm{~m}^{2} \mathrm{~g}^{-1}$ for $\sigma$ as suggested by the manufacturer, although the choice of $\sigma$ is not consequential since it was used to infer relative $\mathrm{EC}$ in metal loaded samples.

\subsection{Metal analysis}

Quartz (after OC/EC analysis) or Teflon filters were immersed in $10 \mathrm{~mL} 5 \% \mathrm{HNO}_{3}$ for $24 \mathrm{~h}$. The resulting solutions were filtered and analyzed for metals by inductively coupled plasma atomic emission spectroscopy (ICP-AES, Perkin-Elmer, TJA Radial Iris 1000). A multiple elements stock solution, containing 10 or $20 \mathrm{ppm}$ of each element was prepared from individual element standards (CPI Intl.). 0.01-1.2 ppm element standards were prepared by serial dilution of the stock solution. $\mathrm{Zn}, \mathrm{Cu}, \mathrm{Fe}, \mathrm{K}, \mathrm{Mg}, \mathrm{Mn}, \mathrm{Ca}$ and $\mathrm{Na}$ in blanks were about 1.4, 1.2, 0.5, 1.0, 0.3, 0.1, 29 and $3.5 \%$ of those in samples, respectively.

\section{Results}

\subsection{Effect of ambient aerosols on TOEGA analyses of diesel particles}

Table 1 shows the metal and carbon content of ambient TSP samples. The composition was quite variable from day to day; metals and carbon comprised $20-45 \%$ and $10-20 \%$ of the total particle mass, respectively. The most abundant metals were $\mathrm{Na}$, followed by $\mathrm{Ca}, \mathrm{Mg}$ and $\mathrm{Fe}$, with $\mathrm{K}, \mathrm{Si}, \mathrm{Cu}$, $\mathrm{Al}$ and $\mathrm{Zn}$ also contributing significantly. The element concentrations, as well as the fraction of carbon and other material in these aerosols are well within the ranges observed by other investigators (Krudysz et al., 2008; IMPROVE, 2010), except for the high sodium levels. High sodium is expected due to the sampling site's close proximity to the coast, and the sea breeze present on sampling days.

Ambient TSP was also collected on a layer of diesel particles to investigate the effects of ambient aerosols on the OC/EC analysis of diesel particles by TOEGA. Figure 1 shows the TOEGA results of ambient TSP, diesel, and the two combined for the 5 December sample set. The addition of ambient TSP to diesel particles did not affect the timing of the carbon volatilization profile during the inert phase $(<320 \mathrm{~s})$, although it appears that some of the diesel OC in the first OC peak evolved later in the presence of ambient aerosol. In the oxygen phase $(>320 \mathrm{~s})$, the small amount 
Table 1. Chemical composition and carbon characteristics of ambient TSP, diesel, and co-deposited ambient and diesel particles.

\begin{tabular}{|c|c|c|c|c|}
\hline Sample & Variable & 5-Dec-07 & 6-Dec-07 & 7-Dec-07 \\
\hline \multirow[t]{18}{*}{ Ambient TSP } & $\mathrm{PM}\left(\mu \mathrm{g} / \mathrm{m}^{3}\right)$ & 79 & 57 & 22 \\
\hline & $\mathrm{Na}\left(\mu \mathrm{g} / \mathrm{m}^{3}\right)$ & 6.44 & 7.48 & 7.42 \\
\hline & $\mathrm{Al}\left(\mu \mathrm{g} / \mathrm{m}^{3}\right)$ & 0.42 & 0.27 & 0.06 \\
\hline & $\mathrm{Ba}\left(\mu \mathrm{g} / \mathrm{m}^{3}\right)$ & 0.15 & 0.06 & 0.02 \\
\hline & $\mathrm{Ca}\left(\mu \mathrm{g} / \mathrm{m}^{3}\right)$ & 2.84 & 1.93 & 0.49 \\
\hline & $\mathrm{Cr}\left(\mu \mathrm{g} / \mathrm{m}^{3}\right)$ & 0.05 & 0.02 & 0.01 \\
\hline & $\mathrm{Cu}\left(\mu \mathrm{g} / \mathrm{m}^{3}\right)$ & 0.37 & 0.07 & 0.02 \\
\hline & $\mathrm{Fe}\left(\mu \mathrm{g} / \mathrm{m}^{3}\right)$ & 1.77 & 0.78 & 0.19 \\
\hline & $\mathrm{K}\left(\mu \mathrm{g} / \mathrm{m}^{3}\right)$ & 0.47 & 0.24 & 0.2 \\
\hline & $\operatorname{Mg}\left(\mu \mathrm{g} / \mathrm{m}^{3}\right)$ & 1.06 & 0.97 & 0.85 \\
\hline & $\mathrm{Ni}\left(\mu \mathrm{g} / \mathrm{m}^{3}\right)$ & 0.01 & 0.01 & 0 \\
\hline & $\mathrm{Si}\left(\mu \mathrm{g} / \mathrm{m}^{3}\right)$ & 0.75 & 0.41 & 0.26 \\
\hline & $\mathrm{Ti}\left(\mu \mathrm{g} / \mathrm{m}^{3}\right)$ & 0.04 & 0.02 & 0 \\
\hline & $\mathrm{V}\left(\mu \mathrm{g} / \mathrm{m}^{3}\right)$ & 0.11 & 0.03 & 0.09 \\
\hline & $\mathrm{Zn}\left(\mu \mathrm{g} / \mathrm{m}^{3}\right)$ & 0.43 & 1.25 & 0.05 \\
\hline & $\mathrm{TC}\left(\mu \mathrm{g} / \mathrm{m}^{3}\right)$ & 15 & 9 & 2 \\
\hline & EC/OC Ratio $^{\mathrm{a}}$ & 0.16 & 0.19 & 0.12 \\
\hline & EC Ox. Temp. ${ }^{\mathrm{b}}\left({ }^{\circ} \mathrm{C}\right)$ & 794 & 723 & 724 \\
\hline \multirow[t]{2}{*}{ Diesel } & EC/OC Ratio $^{\mathrm{a}}$ & 4.97 & 12.1 & 1.02 \\
\hline & EC Ox. Temp. ${ }^{b}\left({ }^{\circ} \mathrm{C}\right)$ & 921 & 916 & 866 \\
\hline \multirow{8}{*}{$\begin{array}{l}\text { Ambient + } \\
\text { Diesel }\end{array}$} & Ambient TC Mass on Filter $(\mu \mathrm{g})$ & 28 & 33 & 11 \\
\hline & Diesel TC Mass on Filter $(\mu \mathrm{g})$ & 171 & 66 & 18 \\
\hline & Metal/TC Ratio ${ }^{c}$ & 0.14 & 0.50 & 1.83 \\
\hline & Expected EC/OC Ratio $^{\mathrm{d}}$ & 2.77 & 2.02 & 0.55 \\
\hline & Measured EC/OC Ratio ${ }^{a}$ & 1.95 & 1.50 & 0.29 \\
\hline & EC/OC Ratio Red. ${ }^{\mathrm{e}}(\%)$ & -30 & -26 & -47 \\
\hline & EC Ox. Temp. ${ }^{\mathrm{b}}\left({ }^{\circ} \mathrm{C}\right)$ & 794 & 720 & 724 \\
\hline & EC Ox. Temp. Red. ${ }^{f}\left({ }^{\circ} \mathrm{C}\right)$ & -127 & -196 & -142 \\
\hline
\end{tabular}

\footnotetext{
${ }^{a}$ Based on instrument split time. ${ }^{b}$ The temperature at which the largest carbon evolution peak appears in the He/O $\mathrm{O}_{2}$-phase. ${ }^{\mathrm{c}}$ Mass ratio of the sum of measured metals in ambient to the sum of ambient TC and diesel TC. ${ }^{\mathrm{d}}$ Weighted average of diesel EC/OC and ambient EC/OC. ${ }^{\mathrm{e}}$ Percent reduction of measured EC/OC ratio to expected EC/OC ratio in ambient + diesel sample. ${ }^{\mathrm{f}}$ Reduction of EC oxidation temperature in ambient + diesel sample to diesel sample.
}

of ambient aerosol shifted the oxidation temperature of the low volatility carbon (EC) in diesel particles $\sim 130-190{ }^{\circ} \mathrm{C}$ earlier; $\mathrm{EC}$ in diesel-ambient samples began to oxidize at the same temperature as EC in ambient aerosols. TOEGA results for the samples from 6 and 7 December were very similar to 5 December (Table 1); the reduction of diesel EC oxidation temperature is independent of the metal/TC ratio. The studies from Turner and Hering (1994) and Grosjean et al. (1994) also showed that exposure of a highway tunnel sample to inland or coastal ambient aerosols resulted in a $\sim 100^{\circ} \mathrm{C}$ or $\sim 150^{\circ} \mathrm{C}$ reduction of soot oxidation temperature, respectively. The authors suggested that sodium or other components in ambient aerosols catalyzed the oxidation of carbon. These results reiterate that components in ambient aerosols can cause diesel EC to start oxidizing almost immediately after oxygen is introduced, in the region where POC evolves, making accurate separation of OC and EC very difficult.
For the 5 December sample set, the EC/OC ratios were 4.97, 0.16 and 1.95 for diesel, ambient TSP, and the two combined, respectively. Based on the TC mass of diesel $(171 \mu \mathrm{g})$ and ambient TSP $(28 \mu \mathrm{g})$ in the combined sample, the weighted EC/OC ratio of the resulting mixture would be 2.77. This ratio is higher than the measured ratio of 1.95 , suggesting components of the ambient particles reduce the EC/OC ratio of diesel particles measured by TOEGA. Similar results were found for the other two sample sets (Table 1).

\subsection{Effect of metal catalysts on TOEGA analyses of diesel particles}

$\mathrm{Na}, \mathrm{K}, \mathrm{Mg}, \mathrm{Ca}, \mathrm{Fe}$ (II, III), $\mathrm{Cu}$ (I, II), Mn, and $\mathrm{Zn}$ are abundant in ambient aerosols. In this study, chlorides of the above metals were chosen to understand their effects on the $\mathrm{OC}$ and EC measurements of diesel particles by TOEGA. Na, $\mathrm{Cu}(\mathrm{II})$, and $\mathrm{Fe}$ (III) sulfates were also investigated to determine the role of anions. 


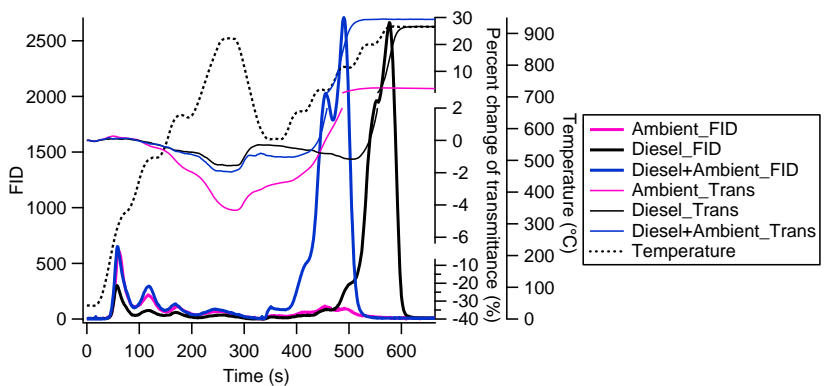

Fig. 1. Carbon evolution profiles, laser transmission signal and oven temperature profile for ambient, diesel, and co-deposited ambient and diesel particles, for samples collected in 5 December 2007. The diesel and ambient particle masses on the filters were $171 \mu \mathrm{g}$ and $28 \mu \mathrm{g}$, respectively.

Comparing the metal mass measured by ICP and SMPS suggests the collected metal particles were likely a combination of metal hydrates and crystalline metal particles (Table S1). The mean diameter of the metal particles was between $~ 70-100 \mathrm{~nm}$ (Fig. S1). The mass of metals (exclusive of water and anions) and carbon on the filters fell in the ranges of 5-164 and 27-226 $\mu \mathrm{g}$, with averages of $36 \pm 31$ and $108 \pm 46 \mu \mathrm{g}$, respectively.

\subsubsection{Effects on TC}

For pure diesel samples, there is a strong correlation between BC measured by optical transmissometer and TC measured by TOEGA, TC $(\mu \mathrm{g})=1.78 \times \mathrm{BC}(\mu \mathrm{g})-21.97\left(R^{2}=0.97\right)$. For metal-loaded diesel samples, we estimated TC $\left(\mathrm{TC}_{\mathrm{esti}}\right)$ from measured $\mathrm{BC}$ and the above linear relationship, and compared it to measured $\mathrm{TC}$ ( $\left.\mathrm{TC}_{\text {meas }}\right)$. $\mathrm{TC}_{\text {meas }}$ is strongly correlated with $\mathrm{TC}_{\text {esti }}\left(\mathrm{TC}_{\mathrm{esti}}=0.998 \times \mathrm{TC}_{\text {meas }}-0.516 ; R^{2}=\right.$ 0.88 ) for all metal-loaded diesel samples (Fig. S2). While there is more scatter for the metal-loaded samples, the slope of regression line is not differentiable from 1, suggesting that the metal catalysts do not affect the TC measurement by TOEGA.

\subsubsection{Effects on carbon oxidation}

Figure 2 shows average TOEGA thermograms of metalloaded and pure diesel samples. For 13 diesel controls without metal catalysts, the native EC was oxidized at $\sim 870^{\circ} \mathrm{C}$, corresponding to the largest peak at $\sim 550 \mathrm{~s}$. At this point, $80 \%$ of the carbon has evolved from the filter. This point, $T_{0.8}$ is used to compare the effect of metal salts on carbon evolution. With metal catalysts, a more complex carbon evolution profile was observed. Once oxygen is introduced, the carbon begins to oxidize earlier, and some evolves at each temperature step, resulting in the multiple peaks in the oxidative phase. The carbon is also completely removed from the filter at lower temperatures.
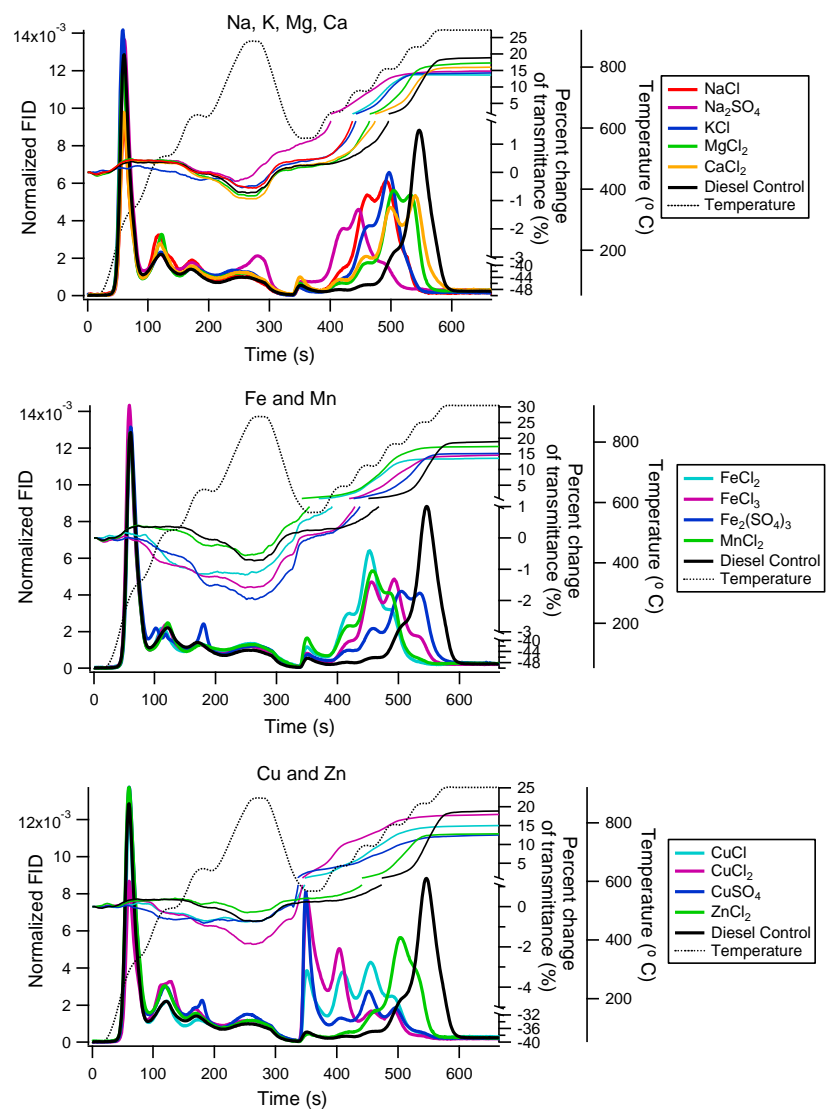

Fig. 2. Carbon evolution profiles of diesel and metal-loaded diesel samples using the NIOSH protocol. For each metal salt, several samples with different metal to carbon ratios were averaged. The diesel control profile is also an average, of 13 samples. The FID response was normalized to the total FID response ( $\Delta$ FID/ $\Sigma$ FIDdt). Transmittance profiles are shown as percent change relative to the initial transmittance $\mathrm{I}_{0}$, i.e. $\left(\operatorname{lnI}-\ln \mathrm{I}_{0} / \ln \mathrm{I}_{0}\right) \times 100$.

Due to the multiple oxidation steps of diesel EC in the presence of metal catalysts, the fraction of carbon conversion as a function of temperature in the oxygen phase was calculated for metal-loaded and pure diesel samples and shown in Fig. S3. It shows clearly that metals systematically lower the temperature at which the carbon evolves from the filter.

The average degrees by which each metal salt reduces the native EC oxidation temperature $\left(T_{0.8}\right)$ are as follows: (in ${ }^{\circ} \mathrm{C}$ ) $\mathrm{CuCl}-133, \mathrm{CuCl}_{2}-212, \mathrm{CuSO}_{4}-193, \mathrm{FeCl}_{2}-145, \mathrm{FeCl}_{3}$ -93, $\mathrm{Fe}_{2}\left(\mathrm{SO}_{4}\right)_{3}-54, \mathrm{MnCl}_{2}-131, \mathrm{ZnCl}_{2}-64, \mathrm{NaCl}-94$, $\mathrm{Na}_{2} \mathrm{SO}_{4}-156, \mathrm{KCl}-76, \mathrm{MgCl}_{2}-48$, and $\mathrm{CaCl}_{2}-22$. Copper (II) species had the largest effect, causing the oxidation of carbon immediately after the addition of oxygen; calcium and magnesium had little effect $\left(\mathrm{MgCl}_{2}>\mathrm{CaCl}_{2}\right)$; iron (II, III), copper (I), manganese, zinc, sodium, and potassium all had moderate effects $\left(\mathrm{KCl}>\mathrm{NaCl} ; \mathrm{CuCl}, \mathrm{FeCl}_{2}\right.$, $\mathrm{MnCl}_{2}>\mathrm{FeCl}_{3}>\mathrm{ZnCl}_{2}$ ). The reduced form of iron was more active than its oxidized form; while the oxidized form 
of copper was more active than its reduced form. The effect of anions on carbon oxidation also varied by metal. Sodium sulfate was more active than sodium chloride, while copper and iron chlorides were more active than sulfates.

The importance of catalyst concentration on EC oxidation was investigated by considering the reduction of $T_{0.8}$ (compared to pure diesel $T_{0.8}$ ) as a function of $\mathrm{M} / \mathrm{C}$ ratio. The oxidation reactivity was found to be independent or very weakly dependent on the catalyst concentration for most metals (Fig. S4). Such independence of $T_{0.8}$ on metal loading may be because the quantity of metals that is sufficient to lower the carbon oxidation temperature is below the lowest ratio we used (between 0.03 and 0.37 depending on the metal).

The results indicate that catalytic activity of metal salts depends on the metal, its oxidation state, and to a lesser degree on the associated anions. The general activity follows transition metal $>$ alkali metal $>$ alkaline-earth metal.

A handful of previous studies on the catalytic oxidation of soot support our results. For the oxidation of model soot (Printex-U), $\mathrm{CuCl}_{2}$ and $\mathrm{CuCl}$ were very active, whereas $\mathrm{CaCl}_{2}$ had little effect (Mul et al., 1998). $\mathrm{Cu}\left(\mathrm{NO}_{3}\right)_{2}$ was the most effective catalyst of the first transition series of elements in carbon-air reactions $\mathrm{Cu}\left(\mathrm{NO}_{3}\right)_{2} \gg \mathrm{Fe}\left(\mathrm{NO}_{3}\right)_{3}>\mathrm{Mn}\left(\mathrm{NO}_{3}\right)_{2}>\mathrm{Zn}\left(\mathrm{NO}_{3}\right)_{2}$ (MorenoCastilla et al., 1985). $\mathrm{CuO}$ was a better catalyst than $\mathrm{Cu}_{2} \mathrm{O}$ and $\mathrm{Fe}_{2} \mathrm{O}_{3}$ (Neri et al., 1997; Neeft et al., 1998; Wang and Haynes, 2003). $\mathrm{Cu}^{2+}$ ion was the active form for copper reagents, and copper was more active in the presence of chloride than other anions (Courcot et al., 1998). $\mathrm{CuCl}_{2}$ could lower the oxidation temperature of diesel soot by $\sim 170^{\circ} \mathrm{C}$ (Murphy et al., 1981). K reduced the oxidation temperature of $\mathrm{BC}$ in biomass aerosols by $\sim 100^{\circ} \mathrm{C}$ (Novakov and Corrigan, 1995b). Na lowered the combustion temperatures of laboratory-generated (Lin and Friedlander, 1988), biomass $\left(\sim 100^{\circ} \mathrm{C}\right.$, Novakov and Corrigan, $\left.1995 \mathrm{~b}\right)$, and ambient tunnel $\left(\sim 50^{\circ} \mathrm{C}\right.$, Grosjean et al., 1994$)$ carbonaceous particles.

The catalytic activity of metals on soot oxidation is related to many factors, such as the type of contact between the catalyst and soot, the origin and structure of soot itself, and the catalyst mobility, dispersion, sintering or inhibition, so some variation between studies is inevitable.

\subsubsection{Effect on OC charring}

Figure 2 shows that during the inert heating phase of TOEGA $(<320 \mathrm{~s})$, there is a small decrease in laser transmittance for both metal-loaded and pure diesel samples, indicating some OC charring. The fraction of charred OC was quantified from the change in the transmission signal, calculated as the percent reduction of laser transmittance through the filter during the inert heating phase of TOEGA, i.e. $\left(\ln \mathrm{I}_{\max }\right.$ $\left.-\ln \mathrm{I}_{\min }\right) / \ln \mathrm{I}_{\max } \times 100$, where $\mathrm{I}_{\max }$ and $\mathrm{I}_{\min }$ denote the maximum and minimum transmission signals during the inert phase, respectively. As expected (Yu et al., 2002), char
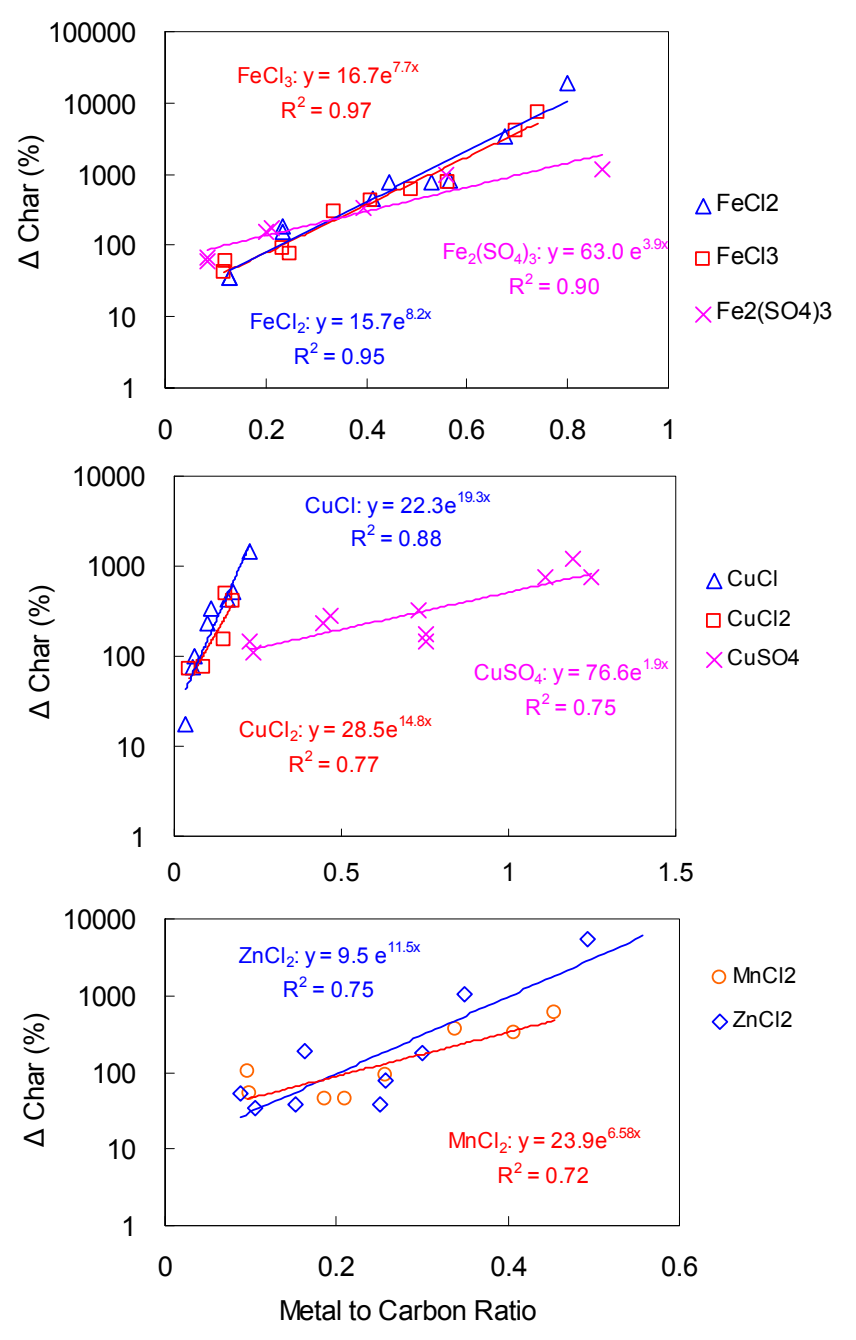

Fig. 3. The percent increase of char as a function of metal to carbon ratio for transition metal-loaded diesel compared to diesel reference samples. The values have been adjusted for the mass of TC (see text). The y-axis represents ([char $]_{\text {metal-loaded diesel sample }}{ }^{-}$ $[\mathrm{char}]_{\text {diesel reference sample with matched TC loading }) /}$

$[\mathrm{char}]_{\text {diesel reference sample with matched TC loading }} \times 100$. Char: the percent reduction of laser transmittance through the filter during the inert heating phase of TOEGA.

was strongly linearly correlated with the TC loading, which ranged from 35-360 $\mu \mathrm{g}$ per filter, for diesel reference samples (Fig. S5a):

$\operatorname{char}(\%)=0.0378 \mathrm{TC}(\mu \mathrm{g})-1.47\left(R^{2}=0.92\right)$

The effect of metals on OC charring was investigated by calculating the percent change of char for metal-loaded diesel relative to diesel reference samples (Figs. 3 and S6). Char of a metal-loaded diesel sample was calculated from its transmittance profile. Since metal-loaded and diesel reference samples have different TC loadings, the reference char was calculated from Eq. (1) using the measured TC for the 
metal-loaded sample. All tested salts increase char to variable extents (Figs. 3 and S6). Increased charring by transition metal salts was dependent on the $\mathrm{M} / \mathrm{C}$ ratio, while the effects of alkali and alkaline-earth metals were not. The presence of alkali and alkaline-earth metal salts, $\mathrm{NaCl}, \mathrm{Na}_{2} \mathrm{SO}_{4}, \mathrm{KCl}$, $\mathrm{MgCl}_{2}$, and $\mathrm{CaCl}_{2}$ caused increases of $26 \pm 26 \%, 65 \pm 143 \%$, $107 \pm 106 \%, 90 \pm 117 \%$ and $52 \pm 70 \%$ in char, respectively. Figure 3 shows that $\mathrm{Cu}$ and $\mathrm{Fe}$ increase $\mathrm{OC}$ charring rapidly with $\mathrm{M} / \mathrm{C}$ ratio, following an exponential relationship in the $\mathrm{M} / \mathrm{C}$ range of $0.03-1.25$. For both $\mathrm{Fe}$ and $\mathrm{Cu}$ salts, chlorides are more active than sulfates. The results also suggest that the oxidation state of the transition metal has little effect on OC charring.

\subsubsection{Effects on OC-EC split time}

The split time is manually set at the point where the laser transmittance returns to its initial maximum level. For diesel reference samples, the split time was correlated with the TC loading, increasing modestly as TC increased, $t_{\text {split }}$ $(\mathrm{s})=0.5585 \mathrm{TC}(\mu \mathrm{g})+336.24$ with $R^{2}=0.52, \quad p<0.001$ (Fig. S5b). Heavily loaded filters are less likely to give significant increases in laser transmittance as the oven temperature approaches $900^{\circ} \mathrm{C}$ in the inert phase and these filters are therefore likely to have the OC-EC split occur later in the oxygen phase (Peterson and Richards accessed July 2010).

The effect of metals on the OC-EC split of diesel samples was investigated by comparing the OC-EC split between metal-loaded and pure diesel samples normalized to the same TC loading. Generally, the metals lowered the split time, although there were a few scattered samples that had negligible or positive changes (Fig. S7). Most did not show a dependence on $\mathrm{M} / \mathrm{C}$ ratio, however, $\mathrm{CuCl}, \mathrm{CuCl}_{2}, \mathrm{FeCl}_{2}$, and $\mathrm{ZnCl}_{2}$ did, with smaller changes in the split time as $\mathrm{M} / \mathrm{C}$ increased.

Figure 4 shows the relationship between the drop of OCEC split time and the reduction of EC oxidation temperature $\left(T_{0.8}\right)$ in the presence of metals. The data show a strong positive correlation $\left(R^{2}=0.73\right)$ between the two factors, although the variations of both changes are large. No correlation between OC-EC split and OC charring is found (not shown). The result suggests that the location of OC-EC split is more a function of the removal of EC from the filter than OC charring. The split point corrections produced by the instrument software, as with all other analyses, show a similar strong correlation (not shown).

\subsubsection{Effects on EC/OC ratio}

Figure 5 shows the EC/OC ratio as a function of $\mathrm{M} / \mathrm{C}$ ratio. Most of the metal-M/C ratio combinations lower the EC/OC ratio by a substantial amount. $\mathrm{Fe}_{2}\left(\mathrm{SO}_{4}\right), \mathrm{FeCl}_{2}$, $\mathrm{FeCl}_{3}, \mathrm{CuSO}_{4}, \mathrm{Na}_{2} \mathrm{SO}_{4}, \mathrm{MnCl}_{2}$, and $\mathrm{ZnCl}_{2}$ have little effect below a threshold $\mathrm{M} / \mathrm{C}$ ratio, which ranges from approximately 0.1 to 0.4 , and above this $\mathrm{M} / \mathrm{C}$ ratio they lower

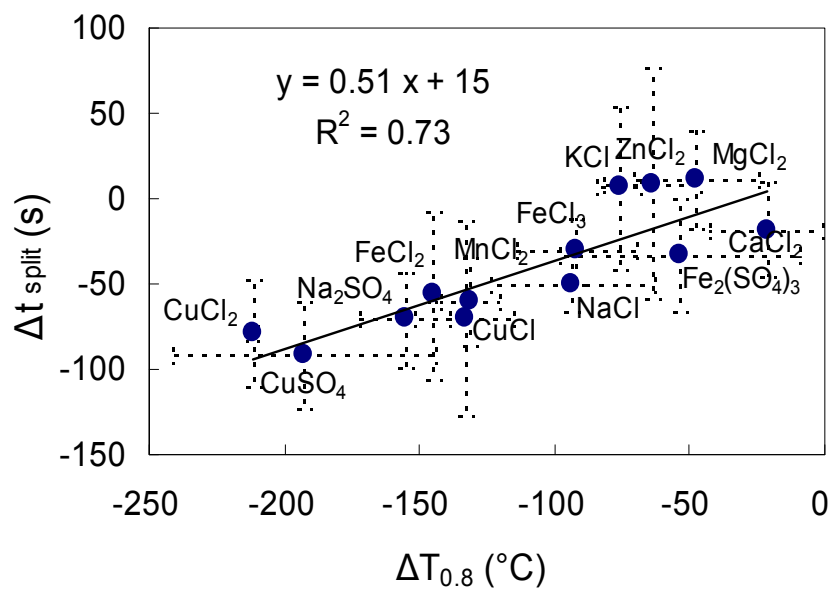

Fig. 4. The reduction of $T_{0.8}$ (temperature at which $80 \%$ of the carbon has evolved from the filter) vs. the reduction of OC-EC split time due to the addition of a metal catalyst. The error bars indicate one standard deviation.

the $\mathrm{EC} / \mathrm{OC}$ ratio. $\mathrm{CaCl}_{2}$ and $\mathrm{CuCl}$ both appear to increase the EC/OC ratios, by $25-40 \%$ at the low end of $\mathrm{M} / \mathrm{C}$ ratios ( 0.03 and 0.06 , respectively), but as $\mathrm{M} / \mathrm{C}$ is increased further, they decrease the EC/OC ratio sharply. Data for $\mathrm{KCl}$ and $\mathrm{CuCl}_{2}$ are difficult to interpret with confidence due to the small number of points and potential that an error in one or two of the points could throw off the conclusion ( 2 of the 4 diesel controls for these salts are anomalously low). They do however lend credence to the notion that for some salts, the $\mathrm{EC} / \mathrm{OC}$ ratio will be increased at low $\mathrm{M} / \mathrm{C}$ ratios. The results for $\mathrm{NaCl}$ are not shown as they are scattered and not in agreement with our preliminary data. We note that samples such as the diesel studied here tend to have more variable split points and EC/OC ratios than ambient samples because they char relatively little and thus are more sensitive to the background correction and small temperature dependent changes in the filter and instrument.

As shown in Fig. 2, the transmittance typically reaches a minimum value partway through the $850^{\circ} \mathrm{C}$ temperature step of the He-mode and then begins increasing, indicating premature evolution of light-absorbing carbon. This loss of light-absorbing carbon in the inert mode could be due to oxidation of POC or native EC due to the presence of inorganic materials, such as metal oxides (Chow et al., 2001) or sulfate (Huffman, 1996), which are able to act as oxidizing agents at high temperatures. In addition, metals catalyze the evolution of more carbon in the lower temperature steps of the $\mathrm{He} / \mathrm{O}_{2}-$ mode (Figs. 2 and S3). The above likely contribute to the lower reported EC/OC ratios in the presence of metals. However, in principle the laser transmittance should do a reasonable job of correcting for such processes and move the split earlier to compensate. A complication arises from the differences in the absorption cross section of POC vs. EC (Yang and $\mathrm{Yu}, 2002)$; POC is usually, more absorbing than EC (e.g., 

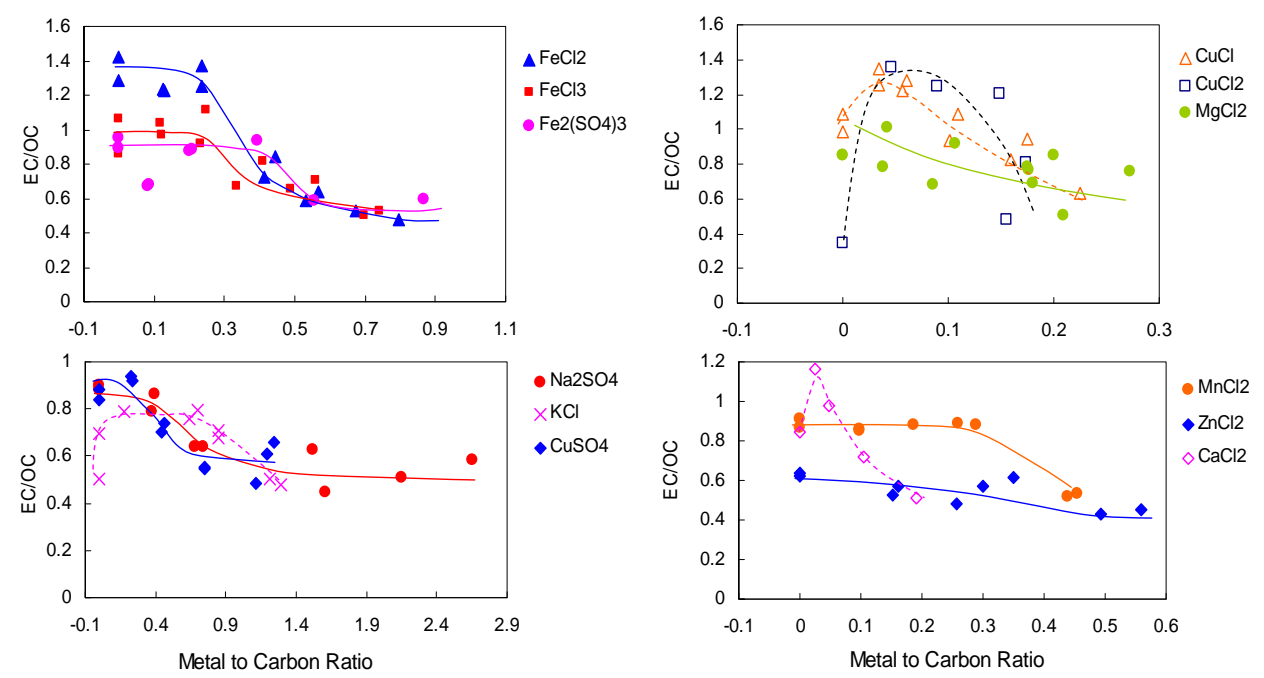

Fig. 5. EC/OC ratio as a function of metal to carbon ratio for metal-loaded diesel and the corresponding diesel reference samples.

Subramanian et al., 2006). This situation can lead to a delayed split point and an underestimate of EC because early evolving EC does not bring the transmission signal back up sufficiently to compensate for the POC that evolves later.

None of the measurable impacts of metals on carbon evolution including its ability to lower the carbon oxidation temperature, to increase $\mathrm{OC}$ charring, and to reduce the split time is correlated with its effect on the EC/OC ratio (not shown). Presumably this is because of the interplay between the effects of metals on carbon evolution, i.e. increasing the OC charring in the He-phase, and catalyzing the oxidation of $\mathrm{POC}$ and $\mathrm{EC}$ both in the $\mathrm{He}$ - and $\mathrm{He} / \mathrm{O}_{2}$-phase.

\subsection{Catalytic mechanisms}

In this study, metal salts were deposited on top of diesel particles. The metal-loaded diesel samples were first heated to $\sim 900^{\circ} \mathrm{C}$ in the absence of $\mathrm{O}_{2}$, allowed to cool, and then reheated to $\sim 900^{\circ} \mathrm{C}$ in the presence of $\mathrm{O}_{2}$. The metal speciation (its chemical form) during the heating process is likely an important factor in the catalytic mechanism of metals. Initially, most of the metal salts exist as hydrates, which presumably dehydrate during the inert heating phase. Eventually the salts reach their melting point, partially vaporize and likely become oxides. The chemical forms of metals during the heating stages in this study are not known, and it is possible chlorides, oxides, and other oxygen-chloride complexes coexist with elemental forms of the metal.

The catalytic activity of metals is related to its physical and chemical properties. The contact between metal and carbon has been found to be an important factor affecting its catalytic activity (Neeft et al., 1996). For metals in loose contact with soot (as in this work), the mobility of a metal is suggested to be a major parameter determining its activity, and the mobility correlates with the melting point (Neri

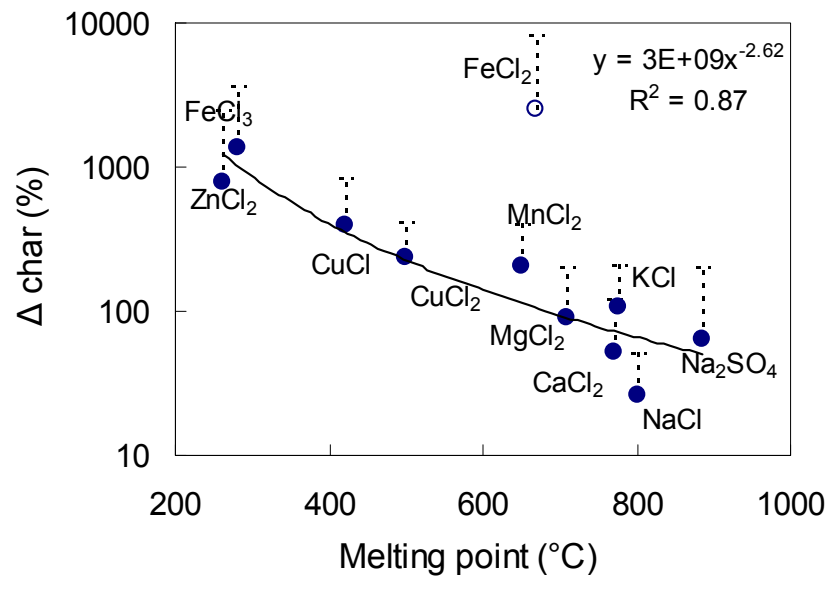

Fig. 6. The percent increase in the fraction of charred OC for metalloaded compared to diesel reference samples vs. the melting point of metal salts. The error bars indicate one standard deviation.

et al., 1997; Neeft et al., 1996; McKee, 1983; Mul et al., 1998; Stanmore et al., 2001). The NIOSH protocol used here reaches temperatures close to $900{ }^{\circ} \mathrm{C}$, above the melting points of all the salts tested. Figure 6 shows that with the exception of $\mathrm{FeCl}_{2}$, which is excluded from the regression analysis, lower melting points of metal salts are strongly correlated with increasing char $\left(y=3 \mathrm{E}+09 \times^{-2.6228}, R^{2}=0.87\right)$.

The melting point of metal salts is not correlated with the shift in EC oxidation temperature (not shown), likely because the metal salts are converted to other chemical forms (oxides, oxygen-chloride complexes) in the $\mathrm{He} / \mathrm{O}_{2}$-phase. It also suggests that the chemical properties of metal catalysts, beyond simple contact with carbon, play an important role in the oxidation of EC. 
Metal chlorides may catalyze the carbon oxidation through the formation of $\mathrm{M}-\mathrm{O}-\mathrm{Cl}$ species; the catalytic cycle is proposed involving activation of oxygen on the surface of the metal(oxy)chloride, followed by transfer of activated oxygen to the carbon surface (Mul et al., 1998). The catalytic effect is due to the fact that carbon adsorbs metal-bound oxygen faster than molecular oxygen. Our observation that copper and iron are more active in the presence of chloride than sulfate lends some credence to the above mechanism. Another mechanism accounting for the catalytic activity of metal chlorides is through the coordination between metal ions and oxygen-containing ligands in diesel particles including $\mathrm{O}^{2-}, \mathrm{OH}^{-}, \mathrm{H}_{2} \mathrm{O}$ and $-\mathrm{COO}^{-}$. The formation of metaloxygen complexes through coordination of metal ions will greatly change the structure of diesel particles, which will affect its oxidation properties (Yu et al., 2005).

Metal oxides, which may form upon heating, are known to catalyze carbon oxidation through oxygen transfer mechanisms. $\mathrm{CuO}, \mathrm{Cu}_{2} \mathrm{O}, \mathrm{Fe}_{2} \mathrm{O}_{3}, \mathrm{ZnO}, \mathrm{MgO}, \mathrm{CaO}$, and $\mathrm{K}_{2} \mathrm{O}$ have all been shown to have this activity. Metal oxides that readily change valency (such as $\mathrm{Cu}$ and $\mathrm{Fe}$ ) have been identified as superior catalysts (Silva et al., 1997; Setzer et al., 1993; Moulijn et al., 1984). The high activity of transition metals observed in this study suggests the possible role of the above mechanism in the oxidation of diesel EC.

\section{Discussion and atmospheric implications}

Precise quantification of EC is highly desirable due to its relatively large role in climate forcing, in altering the hydrologic cycle when deposited on snow, and because it is commonly used as a tracer for diesel exhaust in urban areas. As we show, the EC and OC measurements of diesel particles by TOEGA is affected by metals in the sample. Metals change the evolution profiles of carbon, catalyzing the oxidation of EC and the charring of OC; and generally reduce the EC/OC ratio. Transition metals are more active than alkali and alkaline-earth metals. Since the effect of metals on the EC/OC ratio depends on both metal and $\mathrm{M} / \mathrm{C}$, and further, preliminary measurements in our lab support the catalyst community's suggestion the effects of metals are not simply additive, it is difficult to predict the activity of different metals and the impact of metals on EC/OC analysis of a particular ambient sample. The effect is large however; metals appear to result in negative biases of up to $80 \%$. For a few metal salts, and at low $\mathrm{M} / \mathrm{C}$ ratios, the EC/OC ratio may be increased as by as much as $40 \%$.

Pure diesel contains variable but usually small amounts of metals. For our diesel particles the M/C ratio for metals tested here is about 0.02 , similar to the ultrafine fraction in Southern California (Krudysz et al., 2008). This may itself cause errors in the reported EC; our results suggest the direction of the error could be in the direction of over-reporting EC. For fine mode particles $\mathrm{M} / \mathrm{C}$ ratios are usually $0.1-0.5$, and the upper end of the range may be even higher for $\mathrm{PM}_{10}$ and TSP (Krudysz et al., 2008; IMPROVE 2010 and Table 1), thus underestimates of EC are likely more common in ambient samples. If metals react similarly with different types of carbonaceous aerosols present in ambient aerosols, the measured EC/OC ratio will likely have a variable, low bias except possibly at very low $\mathrm{M} / \mathrm{C}$ ratios. This is supported by the dramatic reductions in EC/OC ratios we observed in our mixtures of diesel with ambient aerosol (Sect. 3.1).

Although more work would clearly be required, including investigation of the effect of aluminum and silicon, which may also have catalytic activity, there is potential that existing data sets containing EC, OC and trace metals could be corrected. We also note that adjusting the temperature profile to minimize charring will not necessarily reduce metaldependent errors in EC/OC splits because the split point is more sensitive to changes in EC oxidation temperature than it is to charring.

\section{Supplement related to this article is available online at: http://www.atmos-chem-phys.net/10/11447/2010/ acp-10-11447-2010-supplement.pdf.}

Acknowledgements. This work was supported by the Department of Energy's Atmospheric Science Program (Office of Science, BER, Grant No. DE-FG02-05ER64011:A004). We gratefully acknowledge UCLA colleagues J. Froines and A. Eiguren Fernandez for access and support using the evolved gas analyzer, assistance from L. Lackey, and helpful discussions with S. Senkan.

Edited by: M. Ammann

\section{References}

Birch, M. E., and Cary, R. A.: Elemental carbon-based method for monitoring occupational exposure to particulate diesel exhaust, Aerosol Sci. Technol., 25, 221-241, 1996.

Bonnefoy, F., Gilot, P., Stanmore, B. R., and Prado, G.: A comparative study of carbon black and diesel soot reactivity in the temperature range 500-600 DegC. Effect of additives, Carbon, 32, 1333-1340, 1994.

Chow, J. C., Watson, J. G., Crow, D., Lowenthal, D. H., and Merrifield, T.: Comparison of IMPROVE and NIOSH carbon measurements, Aerosol Sci. Technol., 34, 23-34, 2001.

Chung, A., Lall, A. A., and Paulson, S. E.: Particulate emissions by a small non-road diesel engine: Biodiesel and diesel characterization and mass measurements using the extended idealized aggregates theory, Atmos. Environ., 42, 2129-2140, 2008.

Courcot, D., Abi-Aad, E., Capelle, S., and Aboukais, A.: Investigation of copper-cerium oxide catalysts in the combustion of diesel soot, Stud. Surface Sci. Catal., 116, 625-634, 1998.

Gray, H. A., and Cass, G. R.: Source contributions to atmospheric fine carbon particle concentrations, Atmos. Environ., 32, 3805$3825,1998$. 
Grosjean, D., Williams, E. L., II, Grosjean, E., and Novakov, T.: Evolved gas analysis of secondary organic aerosols, Aerosol Sci. Technol., 21, 306-324, 1994.

Huebert, B. J., and Charlson, R. J.: Uncertainties in data on organic aerosols, Tellus B: Chem. Phys. Meteorol., 52B, 1249$1255,2000$.

Huffman, H. D.: The reconstruction of aerosol light absorption by particle measurements at remote sites: an independent analysis of data from the IMPROVE network - II, Atmos. Environ., 30, 85-99, 1996.

IMPROVE: Interagency monitoring of protected visual environments, avalable online at: http://vista.cira.colostate.edu/improve/ Data/IMPROVE/improve_data.htm, 2010.

Krudysz, M. A., Froines, J. R., Fine, P. M., and Sioutas, C.: Intracommunity spatial variation of size-fractionated PM mass, OC, $\mathrm{EC}$, and trace elements in the Long Beach, CA area, Atmos. Environ., 42, 5374-5389, 2008.

Lin, C. and Friedlander, S. K.: Soot oxidation in fibrous filters. 2. Effects of temperature, oxygen partial pressure and sodium additives, Langmuir, 4, 898==903, 1988.

McKee, D. W.: Mechanisms of the alkali metal catalysed gasification of carbon, Fuel, 62, 170-175, 1983.

Moreno-Castilla, C., Rivera-Utrilla, J., Lopez-Peinado, A., Fernandez-Morales, I., and Lopez-Garzon, F. J.: Gasification reaction of a lignite char catalyzed by chromium, manganese, iron, cobalt, nickel, copper and zinc in dry and wet air, Fuel, 64, 12201223, 1985.

Moulijn, J. A., Cerfontain, M. B., and Kapteijn, F.: Mechanism of the potassium catalysed gasification of carbon in $\mathrm{CO}_{2}$, Fuel, 63, 1043-1047, 1984.

Mul, G., Neeft, J. P. A., Makkee, M., Kapteijn, F., and Moulijn, J. A.: Catalytic oxidation of model soot by chlorine based catalysts, Stud. Surface Sci. Catal., 116, 645-654, 1998.

Murphy, M. J., Hillenbrand, L. J., Trayser, D. A., and Wasser, J. H.: Assessment of diesel particulate control-direct and catalytic oxidation, SAE (Society of Automotive Engineers), paper No. 810112, 1981.

Neeft, J. P. A., Makkee, M., and Moulijn, J. A.: Catalysts for the oxidation of soot from diesel exhaust gases. I. An exploratory study, Appl. Catal. B: Environ., 8, 57-78, 1996.

Neeft, J. P. A., Makkee, M., and Moulijn, J. A.: Catalytic oxidation of carbon black. I. Activity of catalysts and classification of oxidation profiles, Fuel, 77, 111-119, 1998.

Neri, G., Bonaccorsi, L., Donato, A., Milone, C., Musolino, M. G., and Visco, A. M.: Catalytic combustion of diesel soot over metal oxide catalysts, Appl. Catal. B 11, 217-231, 1997.

NIOSH: Elemental Carbon (Diesel Particulate), NIOSH Manual of Analytical Methods (NMAM), NIOSH, Method 5040 Issue 5043, 1999.

Novakov, T. and Corrigan, C. E.: Thermal characterization of biomass smoke particles, Mikrochimica Acta, 119, 157-166, 1995a.

Novakov, T. and Corrigan, C. E.: Influence of sample composition on aerosol organic and black carbon determinations, Proceedings, 1995 Chapman Conference on Biomass Burning, LBL37513, UC-407, 1995b.

Peterson, M. R. and Richards, M. H.: Thermal-opticaltransmittance analysis for organic, elemental, carbonate, total carbon, and OCX2 in PM2.5 by the EPA/NIOSH method - \#83, available online at: http://www.rti.org/pubs/OC-EC_Paper_83 83b.pdf, last access: July 2010.

Peterson, M. R., Richards, M. H., and Jayanty, R. K. M.: Thermaloptical analysis for organic, elemental, carbonate, and total carbon in $\mathrm{PM}_{2.5}$, International Symposium on the Measurement of Toxic and Related Air Pollutants, Research Triangle Park, NC, USA, 12-14 September 2000, 1-15, 2001.

Ponder, G. R. and Richards, G. N.: Oxygen and $\mathrm{CO}_{2}$ gasification of chars from wood treated with iron(II) and iron(III) sulfates, Energy Fuels, 8, 705-713, 1994.

Richards, G. N. and Zheng, G.: Influence of metal ions and of salts on products from pyrolysis of wood: applications to thermochemical processing of newsprint and biomass, J. Anal. Appl. Pyrol., 21, 133-146, 1991.

Setzer, C., Schutz, W., and Schuth, F.: Transition metal compound oxide catalysts for lowering the light-off temperature of particles from diesel exhaust, In: Proceedings 10th international congress on catalysis, Budapest, Hungary, Amsterdam, Elsevier, 26292632, 1993.

Silva, I. F., McKee, D. W., and Lobo, L. S.: A kinetic and in situ XRD study of carbon reactions catalyzed by nickel, cobalt, molybdenum, and their mixtures, J. Catal., 170, 54-61, 1997.

Stanmore, B. R., Brilhac, J. F., and Gilot, P.: The oxidation of soot: a review of experiments, mechanisms and models, Carbon, 39, 2247-2268, 2001.

Subramanian, R., Khlystov, A. Y., and Robinson, A. L.: Effect of peak inert-mode temperature on elemental carbon measured using thermal-optical analysis, Aerosol Sci. Technol., 40, 763-780, 2006.

Turner, J. R., and Hering, S. V.: Vehicle contribution to ambient carbonaceous aerosols by scaled thermograms, Aerosol Sci. Technol., 12, 620-629, 1990.

Turner, J. R. and Hering, S. V.: The additivity and stability of carbon signatures obtained by evolved gas analysis, Aerosol Sci. Technol., 21, 294-305, 1994.

Varhegyi, G., Antal, M. J., Jr., Szekely, T., Till, F., Jakab, E., and Szabo, P.: Simultaneous thermogravimetric-mass spectrometric studies of the thermal decomposition of biopolymers. 2. Sugarcane bagasse in the presence and absence of catalysts, Energy Fuels, 2, 273-277, 1988.

Wang, S. and Haynes, B. S.: Catalytic combustion of soot on metal oxides and their supported metal chlorides, Catal. Commu., 4, 591-596, 2003.

Yang, H. and Yu, J. Z.: Uncertainties in charring correction in the analysis of elemental and organic carbon in atmospheric particles by thermo/optical methods, Environ. Sci. Technol., 36, 51995204, 2002.

Yu, J., Xu, J., and Yang, H.: Charring characteristics of atmospheric organic particulate matter in thermal analysis, Environ. Sci. Technol., 36, 754-761, 2002.

Yu, J., Tian, F.-J., Chow, M. C., McKenzie, L. J., and Li, C.-Z.: Effect of iron on the gasification of Victorian brown coal with steam:enhancement of hydrogen production, Fuel, 85, 127-133, 2005.

Zhang, Q., Jimenez, J. L., Canagaratna, M. R., Allan, J. D., Coe, H., Ulbrich, I., Alfarra, M. R., Takami, A., Middlebrook, A. M., Sun, Y. L., Dzepina, K., Dunlea, E., Docherty, K., DeCarlo, P. F., Salcedo, D., Onasch, T., Jayne, J. T., Miyoshi, T., Shimono, A., Hatakeyama, S., Takegawa, N., Kondo, Y., 
Schneider, J., Drewnick, F., Borrmann, S., Weimer, S., Demerjian, K., Williams, P., Bower, K., Bahreini, R., Cottrell, L., Griffin, R. J., Rautiainen, J., Sun, J. Y., Zhang, Y. M., and Worsnop, D. R.: Ubiquity and dominance of oxygenated species in organic aerosols in anthropogenically-influenced Northern Hemisphere midlatitudes, Geophys. Res. Lett., 34, L13801, doi:10.1029/2007GL029979, 2007. 